NBER WORKING PAPER SERIES

MODELING THE TERM STRUCTURE OF INTEREST RATES UNDER NONSEPARABLE

UTILITY AND DURABILITY OF GOODS

Kenneth B. Dunn

Kenneth J. Singleton

Working Paper No. 1415

NATIONAL BUREAU OF ECONOMIC RESEARCH

1050 Massachusetts Avenue

Cambridge, MA 02138

August 1984

We thank members of workshops at Carnegie-Mellon University, Ohio State University, Tulane University, the University of Pennsylvania, Doug Breeden, Rick Green, Tim McGuire, and Chester Spatt for helpful comments on an earlier draft; and Chang-Mo Ahn for research assistance. Financial support for the second author was provided by NSF Grant SES-8121253. The research reported here is part of the NBER's research programs in Economic Fluctuations and Financial Markets and Monetary Economics. Any opinions expressed are those of the authors and not those of the National Bureau of Economic Research. 
NBER Working Paper \#1415

August 1984

\section{Modeling the Term Structure of Interest Rates Under}

Nonseparable Utility and Durability of Goods

\section{ABS TRACT}

This paper investigates the term structure relations implied by a twogood model in which goods are durable and the preference function of consumers may be nonseparable both over time and the decision variables. The parameters characterizing preferences are estimated and the implied restrictions on the comovements of consumptions and the returns from following different investment strategies in bonds are examined. Both the durability of goods (modeled by a linear service technology) and the nonseparability of preferences over services from goods are important factors in explaining the time paths of individual returns. However, substantial evidence against our model is obtained when the restrictions associated with two different investment strategies are studied simultaneously. Specifically, the difference between the sample mean returns are too large relative to the difference between the sample covariances of the returns and the marginal utility from acquiring a unit of the numeraire good. Our findings suggest that these discrepancies are not a consequence of either the relatively small variability in aggregate acquisitions of goods, or our small estimates of relative risk aversion.

Kenneth B. Dunn Graduate School of Industrial Administration Carnegie-Me11on University Pittsburgh, PA 15213 (412) $578-2298$
Kenneth J. Singleton

Graduate School of Industrial. Administration Carnegie-Mellon University Pittsburgh, PA 15213 (412) $578-8838$ 
1. Introduction

Equilibrium term structure relations have been deduced under various assumptions about preferences, technology, and the joint distribution of the underlying sources of uncertainty in the economy. For instance, Cox, Ingersoll and Ross (1978, 1981), Lucas (1978), Hansen and Singleton (1982, 1983), Ferson (1983), Marsh (1983), and Sundaresan (1984), among others, have deduced restrictions on bond returns for parameterizations of models with time-additive preferences defined over a single consumption good. To date, most versions of these models that have been implemented empirically have not been consistent with the observed comovements of asset returns and consumption. 1 These findings, together with the complementary evidence reported here, suggest that the representations of returns implied by models with time-additive utility do not capture the relative or absolute risks associated with investing in bonds with different maturities.

In this paper we explore the relations among optimal consumption decisions and the (real) term structure of discount bond returns in the context of a dynamic model in which preferences of consumers are non-time-separable functions of purchases of nondurable and durable goods. The choice of this framework is motivated primarily by the following two considerations. First, by introducing durable goods into the consumers' choice problem and allowing for interactions among the utilities obtained from durable and nondurable goods, we may be able to represent more accurately the linkages between consumption choices and interest rates. In particular, the demands for consumption goods depend not only on the current prices of goods, but also on the rates at which current consumption can be exchanged for consumption at future dates. This 
dependence has been evidenced recently in the large fluctuation in demand for durable goods corresponding to the historically large fluctuation in interest rates. Second, even though preferences in terms of services from goods are time-separable, the durability of goods and the associated technology for producing service flows from these goods induce a nonseparable utility function with purchases of goods as the arguments. We show that an implication of non-time-separability of utility is that shifts in the term structure may affect demands for consumption goods directly, and not only through the marginal utility of wealth as in the case of time-separable preferences. As a consequence, there is potentially more scope for bonds with different terms to maturity to differ in their risk characteristics.

The remainder of this paper is organized as follows. In section two we describe the equilibrium relations among marginal rates of substitution of consumption and returns on bonds with different maturities that form the basis of our empirical analysis. Empirical evidence suggesting that the "consumption risk" inherent in a single-good model with constant relative risk averse preferences cannot explain the average, real returns on U.S. Treasury bills with various maturities is also presented. Our non-time-separable specification of preferences for nondurable and durable goods is described in section three. There we also make more precise the manner in which the marginal utilities from acquiring goods depend on the durable character of goods. The time series properties of these marginal utilities, and in particular their covariability with returns, are potentially very different than those of the marginal utilities from single-good models. 
In section four we describe the data and econometric methodology used in estimation. In addition, it is shown that the specification of the technology for producing services from goods, together with the maturities of the bonds studied, determine the autocovariance structure of the disturbances in our estimation equations. In section five the parameter estimates are presented and the extent to which the restrictions, implied by our model, on the moments of consumptions and returns on securities with different terms to maturity is assessed. In addition to using formal statistical procedures, the fit of our model is evaluated by comparing the sample means of the returns to the sample versions of the corresponding covariance expressions which, according to the theory, equal the mean returns. The sensitivity of these expressions to changes in the parameters governing relative risk aversion and the non-separability over time of preferences is also investigated. Concluding remarks are presented in section six. 


\section{Equilibrium Term Structure Relations}

In this section we describe an equilibrium relation among bond returns that is implied by a large class of dynamic models. Additionally, we present some new evidence that a single-good version of the term structure relation with time-separable utility is not consistent with the risk structure of discount bonds. These observations serve to motivate our non-time-separable, multi-good specification of preferences which is presented in section three.

Suppose that, among other investment opportunities, consumers are given the choice of $K$ investment strategies involving default-free, pure-discount bonds. These strategies may include, for example, buying an $\ell$-period bond and selling it after $n$ periods $(n \leq l)$, or rolling over a sequence of $n$ one-period bonds. Let $r_{t, n}^{k}$ denote the total return cone plus the rate of return) from following the kth investment strategy from date $t$ to date $t+n$, where prices and payoffs are denominated in terms of a numeraire good. 2 Also, suppose that the uncertain economic environment is such that the first-order conditions of a typical consumer's intertemporal optimum problem imply the relation ${ }^{3}$

$$
E_{t}\left[m_{t, n} r_{t, n}^{k}\right]=1, \text { for } k=1,2, \ldots, k \text {, }
$$

where $m_{t, n}$ is an individual consumer's marginal rate of substitution of consumption of the numeraire good at date $t$ for consumption at date $t+n$ and $E_{t}[\cdot]$ denotes the mathematical expectation conditioned on information available at date $t, I_{t}$, which is common to all agents.

To deduce testable restrictions from (1) requires assumptions about preferences, the distributions of $m_{t, n}$ and returns, or possibly both. In order to study the links between acquisitions of goods and returns on 
bonds with different terms of maturity, without imposing assumptions on the joint distribution of the endogenous variables $m_{t, n}$ and $r_{t, n}^{k}$, we proceed by restricting only the functional form of utility. Consequentiy, our empirical results are robust to alternative specifications of technology and the distribution of the exogenous shocks. As in previous empirical studies, our specification of preferences allows for exact demand aggregation, so $m_{t, n}$ can be interpreted as the marginal rate of substitution for a representative consumer.

Since we are not assuming that $m_{t, n}$ and $r_{t, n}^{k}$ are drawn from a particular family of distributions, the conditional mean of $\left[m_{t, n} r_{t, n}^{k}\right]$ cannot be evaluated explicitly as a function of the elements of $I_{t}$. Therefore, instead of basing estimation and inference directly on (1), we exploit the implication of (1) that in equilibrium $\left[m_{t, n} r^{k}, n-1\right]$ must be orthogonal to all of the elements of agents' information set. That is,

(2) $E\left[\left(m_{t, n} r_{t, n}^{k}-1\right) z_{t}\right]=0$, for all $z_{t} \in I_{t}$,

where $E\left[{ }^{*}\right]$ denotes the unconditional expectation. ${ }^{4}$ Given a parametric specification of preferences and time series observations on consumptions, the $k^{\text {th }}$ return and a set of instruments, $z_{t}$, a consistent estimator of the population mean in (2) can be constructed without prior knowledge of the distributions of the variables. The orthogonality conditions (2) restrict the comovements among the returns on the $\mathrm{K}$ investment strategies and are the basis of the subsequent empirical analysis.

There is another relation that is implied by (1) and which resembles more closely the restrictions on bond returns tested in the literature on the traditional expectations models. Specifically, forming the difference of the versions of (1) for two returns $r_{t, n}^{k}$ and $r_{t, n}^{j}$ gives 
(3)

$$
E_{t}\left[m_{t, n} r_{t, n}^{k}\right]=E_{t}\left[m_{t, n} r_{t, n}^{j}\right]
$$

which implies that

$$
E\left[m_{t, n}\left(r_{t, n}^{k}-r_{t, n}^{j}\right) z_{t}\right]=0, \text { for all } z_{t} \varepsilon I_{t} \text {. }
$$

Although estimation and inference can proceed using the orthogonality conditions in (4), these latter conditions are not equivalent to (2). More precisely, (2) requires that the mean of $\left[m_{t, n} r_{t, n}^{k} z_{t}\right]$ equal the mean of $z_{t}$ for the $n$-period return on any investment strategy. On the other hand, (4) requires only that the means of the products $\left[m_{t, n} r^{k}, n^{z_{t}}\right]$ be equal for all returns, which is clearly a weaker requirement than (2). Nevertheless, tests based on (4) may be of interest because of tax considerations (see section four).

The equilibrium relations (1) and (3) allow for the relative riskiness of the $K$ investment strategies to vary over the business cycle. This can be seen more directly as follows: From (i) and the definition of conditional covariance it follows that the risk premium for a security with return $r_{t, n}^{j}$ over the riskless real security that pays off a unit of the numeraire at date $t+n$ is

(5) $E_{t}\left[r_{t, n}^{j}\right]-1 / E_{t}\left[m_{t, n}\right]=-\operatorname{Cov}_{t}\left[r_{t, n}^{j}, m_{t, n}\right] / E_{t}\left[m_{t, n}\right]$.

As in Breeden (1979), risk is measured by the conditional covariabilty of returns with the marginal rate of substitution of consumption. Now forming the difference between the respective versions of (5) for strategies $j$ and $k$ gives 
(6) $E_{t}\left[r_{t, n}^{j}\right]-E_{t}\left[r_{t, n}^{k}\right]=-\operatorname{Cov}_{t}\left[m_{t, n}, r_{t, n}^{j}-r_{t, n}^{k}\right] / E_{t}\left[m_{t, n}\right]$.

If the securities are not equivalent in terms of the insurance which they provide against consumption risk, then the conditional covariances of $r_{t, n}^{j}$ and $r_{t, n}^{k}$ with $m_{t, n}$ will differ and, hence, their mean returns will also be different. We emphasize that the tests of the term structure relations (2) and (4) conducted in this paper allow for the conditional covariances in (5) and (6) to vary over time and to change sign. Moreover, it is not necessary to specify precisely how these covariances change over time with changes in the state of the economy. Thus, our empirical methodology is not subject to Cornell's (1981) criticism of tests of asset pricing models based on consumption-beta representations.

Prior to specifying $m_{t, n}$ and deducing our estimation equations from (2) and (4), it will be useful to review previous empirical specifications of dynamic asset pricing models, and to explore in more detail the nature of their rejections. One approach has been to restrict the joint distribution of $m_{t, n}$ and returns and to specify preferences parametrically. For instance, Hansen and Singleton (1983) rejected at conventional significance levels a model of real returns on one-month Treasury bills and stock returns in which preferences were of the constant relative risk averse type and returns were assumed to be jointly lognormally distributed with $m_{t, 1^{*}}$ Subsequently, Ferson (1983) considered three-month Treasury bills and reported a chi square statistic with a marginal significance level of .026 for a quarterly version of the same model. He also found that a model in which consumers exhibit constant absolute risk aversion and in which consumption is assumed to be normally distributed (returns and $m_{t, l}$ are jointly lognormal) could be rejected at 
the .001 level. Together, these findings suggest that the joint hypothesis that (1) obtains and returns and the marginal rates of substitution are lognormally distributed is not supported by the data. This conclusion is evidently not a consequence of mis-measurement of consumption or other non-financial aggregates. One of the tests conducted by Hansen and Singleton (1983) did not require accurate measurement of consumption and allowed for shocks to preferences. The evidence against these asset pricing relations may, of course, be a consequence of imposing distributional assumptions. However, Hansen and Singleton (1982) provide substantial evidence against a single-good model with constant relative risk averse preferences, but without distributional assumptions imposed, using returns on a stock index and a one-period Treasury bill.

To confirm that these observations apply to bond returns with various maturities, and to explore further the nature of the rejections, we re-estimated the single-good model with constant relative risk averse preferences considered in Kansen and Singleton (1982) using Treasury bill returns and orthogonality conditions of the form (2). This particular model is of interest because of the attention it has received in previous theoretical and empirical studies. Furthermore, under the additional assumption that the marginal rates of substitutions and returns are jointly distributed as log-normal variates, a log-linear version of an expectations theory of the term structure of real interest rates can be derived from (3). 5 This log-linear expectations theory embodies as a special case a discrete-tine version of the local expectations theory deduced by $C o x$, Ingersoll, and Ross (1981) from their general equilibrium model under logarithmic utility and by imposing speciai assumptions about the evolution of the state variables in the economy. 6 
Estimates were obtained for the composite consumption good "nondurables plus services" along with the one-month return on one-month Treasury bilis (TBILL1) and the three-month return on three-month Treasury bilis (TBILL3) constructed by Ibbotson and Siquefield (1982) and Huizinga and Mishkin (1983), respectively. The estimation procedure proposed by Hansen and Singleton (1982) assumes that growth rates of consumption and returns are strictly stationary stochastic processes. 7 It does not restrict returns or consumption to be drawn from a specific family of distributions. The results for the time period January 1959 through December 1978 are reported in Table I. Both of the chi square goodness-of-fit statistics for testing the three over-identifying restrictions suggest that the model is not consistent with the data. Furthermore, the estimated coefficients of relative risk aversion (CRRA) are near zero, which seems implausably small.

TABLE I

ESTIMATES FOR A SINGLE-GOOD MODEL JANUARY 1959 THROUGH DECEMBER $1978^{\mathrm{a}}$

\begin{tabular}{ccccc}
\hline Returns & $\hat{C R R A}$ & $\chi^{2}(3)$ & ER & RP \\
\hline TBILL1 & .2066 & 17.62 & $-9.436-05$ & $4.303-07$ \\
& $(.0806)$ & $(.9994)$ & & \\
TBILL3 & .0012 & 12.04 & $-6.505-04$ & $8.749-09$
\end{tabular}

a. Standard errors of the parameter estimates and probability values of the test statistics are given in parentheses. 
It is instructive to interpret these findings using the relations among "consumption risk" and mean returns implied by this model. The risk premium for the return on an n-period investment strategy is given by (5). This expression is not directly useful for our empirical analysis for the same reasons that we are not studying (1). Namely, we do not have explicit expressions for the conditional moments in (5). There is, however, an unconditional counterpart to (5) that also must hold in equilibrium and which is useful for interpreting the empirical results reported in Table $I$. Using (2) and the definition of unconditional covariance, it follows that

(7) $E\left[r_{t, n}^{j}\right]-E\left[z_{t}\right] / E\left[m_{t, n} z_{t}\right]=-\operatorname{Cov}\left[r_{t, n}^{j}, m_{t, n} z_{t}\right] / E\left[m_{t, n} z_{t}\right]$.

The parameters governing preferences must be such that the first and second moments of $m_{t, n}$ are consistent with (7) for all n-period returns on default-free discount bonds and all $z_{t} \varepsilon I_{t}$. In particular, if $z_{t}$ is chosen to be the constant unity, then ( 7 ) simplifies to a relation among the mean "excess return" of $r_{t, n}^{j}$ about $1 / E\left[m_{t, n}\right]$ and the covariance of the return and $m_{t, n}$.

The sample versions of the left and right hand sides of (7), calculated using the estimated values of the preference parameters and setting $z_{t}$ equal to unity, are also displayed in Table $I$ under the headings $E R$ and $R P$, respectively. The magnitudes of $\operatorname{Cov}\left[r_{t, n}^{j}\right.$, $\left.m_{t, n}\right] / E\left[m_{t, n}\right]$ for $\operatorname{TBILL} 1 \quad(n=1)$ and $\operatorname{TBILL} 3(n=3)$ are two and five orders of magnitude too small, respectively, to be consistent with the magnitudes of the sample mean excess returns on the left-hand-side of (7). Moreover, the signs of RP are not consistent with the signs of ER. None of these 
calculations require returns or $m_{t, n}$ to be drawn from a specific family of distributions.

A common feature of previous preference-based studies of the term structure, which may account for their failure to replicate the moment restriction ( 7 ), is that they assume preferences are separable both over time and across decision variables. In the next section we argue that introducing the desired level of consumption of services from durable goods may substantially affect the time-series behavior of consumers' marginal rates of substitution, and their covariability with returns. Consequently, both the left and right hand sides of ( 7 ) will be affected by introducing a richer specification of preferences. Before turning to this discussion, we acknowledge that the exclusion of taxes from many of the previous studies may also explain their findings. 8 The robustness of our empirical results to the introduction of taxes is assessed in section four, where we discuss the implications of introducing a tax on the income of a "representative investor" for the forms of (2) and (4). 
3. Non-time-separable Preferences for Nondurable and Durable Goods

Consumers are assumed to have preferences over the service flows from nondurable and durable goods, and to rank and alternative sequences of consumptions of services using the utility functional ${ }^{9}$

$$
E_{0} \sum_{t=0}^{\infty} B^{t} \frac{1}{\gamma}\left\{c_{t}^{* \delta} d_{t}^{*(1-\delta)}\right\}^{\gamma}, \quad \gamma<1 ; 0<\delta<1 .
$$

In (8), $c_{t}^{*}$ is the consumption of services from nondurables plus services at date $t, d_{t}^{*}$ is the consumption of services from durable goods at date $t$, $\beta \varepsilon(0,1)$ is a subjective discount factor, and $\delta$ and $\gamma$ are preference parameters. In terms of the composite service flow $\left\{c_{t}^{* \delta} d_{t}^{*}(1-\delta)\right\}$, utility is both time separable and of the constant relative risk averse type, with coefficient of relative risk aversion (1- $\gamma$ ). Although utility is a time-separable function of services, it is implicitly a non-time-separable function of the past acquisitions of goods that yield the services. For both discussing the links between shifts in the term structure and consumptions, and the subsequent empirical analysis, we shall work with the "indirect" utility function obtained from (8) by expressing $c_{t}^{*}$ and $d_{t}^{*}$ in terms of past acquisitions of goods.

Following Telser and Graves (1972), all consumers are assumed to have have access to linear technologies that transform consumption goods purchased today into service flows in the future. The service flow $c_{t}^{*}$ is assumed to be given by

$$
c_{t}^{*}=c_{t}+\alpha_{1} c_{t-1}+\alpha_{2} c_{t-2}+\ldots+\alpha_{m} c_{t-m} ; m<\infty .
$$


where $a_{j} \geq 0$, for all $j .{ }^{10}$ The variable $c_{t}^{*}$ is included in ( 8 ) instead of the purcinases of nondurable goods, $c_{t}$, since some of the goods classified as nondurable may in fact provide services for more than one period (one month). By including $m$ lagged values of $c$, we are at the same time assuming that services are provided by nondurable goods for only $m$ periods. All of the empirical relations considered subsequently allow for $c_{t}^{*}=c_{t}\left(\alpha_{j}=0, j=1, \ldots, m\right)$ as a special case.

The technology for producing services from durable goods is also assumed to be linear, with $d_{t}^{*}$ being proportional to the sum of the stock of durable goods held by the consumer at the beginning of period $t, k_{t-1}$, and purchases of durable goods during period $t, d_{t}: d_{t}^{*}=\theta\left(k_{t-1}+d_{t}\right)$, $0<\theta<1$. Under these assumptions, $k_{t}$ is equal to $\left[k_{t-1}+d_{t}\right]$ less the amount of the stock used to produce services:

$$
k_{t}=(1-\theta)\left[k_{t-1}+d_{t}\right]=(1-\theta) \sum_{j=0}^{\infty}(1-\theta)^{j} d_{t-j} \text {. }
$$

Hence, $d_{t}^{*}$ can be expressed as

$$
d_{t}^{*}=\frac{\theta}{1-\theta} k_{t}=\theta \sum_{j=0}^{\infty}(1-\theta)^{j} d_{t-j} \text {. }
$$

With this service technology, $d_{t}^{*}$ depends on the acquisitions of durable goods infinitely far into the past. Substitution of (9) and (11) into (8) gives the desired utility function defined over purchases.

Let nondurable goods be the numeraire. Then the first-order conditions for the maximization of (8) with respect to the decision variables $c_{t}$ and $\dot{d}_{t}$ and subject to the consumer's budget constraint are: 


$$
E_{t} \beta^{t} \delta\left(1+\sum_{j=1}^{m} \alpha_{j} \beta^{j} L^{-j}\right)\left\{c_{t}^{* \delta \gamma-1} d_{t}^{*(1-\delta) \gamma}\right\}=\lambda_{t}
$$

$$
E_{t} B^{t}(1-\delta) \theta[1-(1-\theta) B L-1]^{-1}\left\{c_{t}^{* \delta \gamma} d_{t}^{*(1-\delta) Y-1}\right\}=p_{d t} \lambda_{t}
$$

where $\lambda_{t}$ is the Lagrange multiplier associated with the period $t$ budget constraint (the marginal utility of wealth), $p_{d t}$ is the price of durable goods in terms of the numeraire, $L^{-1}$ is the forward shift operator (i.e., $\left.L^{-j} x_{t}=x_{t+j}\right)$, and $\left[1-(1-\theta) B L^{-1}\right]^{-1}=\sum_{j=0}^{\infty}\left[(1-\theta) B L^{-1}\right]^{j}$. The left-hand-side of (12) is the marginal utility with respect to $c_{t}$ and the left-hand-side of (13) is the marginal utility with respect to $d_{t}$. These expressions state simply that the marginal utilities with respect to $c_{t}$ and $d_{t}$ must equal the marginal utility of wealth in units of $c$ and $d$, respectively.

The marginal utilities of goods in (12) and (13) involve the expected values of the marginal utilities of future services, because goods purchased at date $t$ provide services in both current and future periods. The forms of these relations depend directly on the specifications of the service technologies. For instance, nondurable goods acquired at date $t$ provide services for $m$ future periods according to ( 9 ). The term $e^{t+j} \delta E_{t}\left\{c_{t+j}^{* \delta \gamma-1} d_{t+j}^{*(1-\delta) Y}\right\}$ in (12) is the expected value to the consumer at date $t$ of an incremental increase in the consumption of services from nondurable goods at date $t+j$. The weight $a_{j}$ (divided by $1+\sum_{j=1}^{m} a_{j}$ ) is the proportion of a unit of services provided at date $t+j$ by the acquisition of goods at $t$. Thus, in utility terms, the services provided at date $t+j$ by an acquisition of nondurable goods at date $t$ contribute $\alpha_{j} \beta^{t+j} \delta E_{t}\left\{c_{t+j}^{* \delta \gamma-1} d_{t+j}^{*(1-\delta) Y}\right\}$ to the total marginal utility obtained from the 


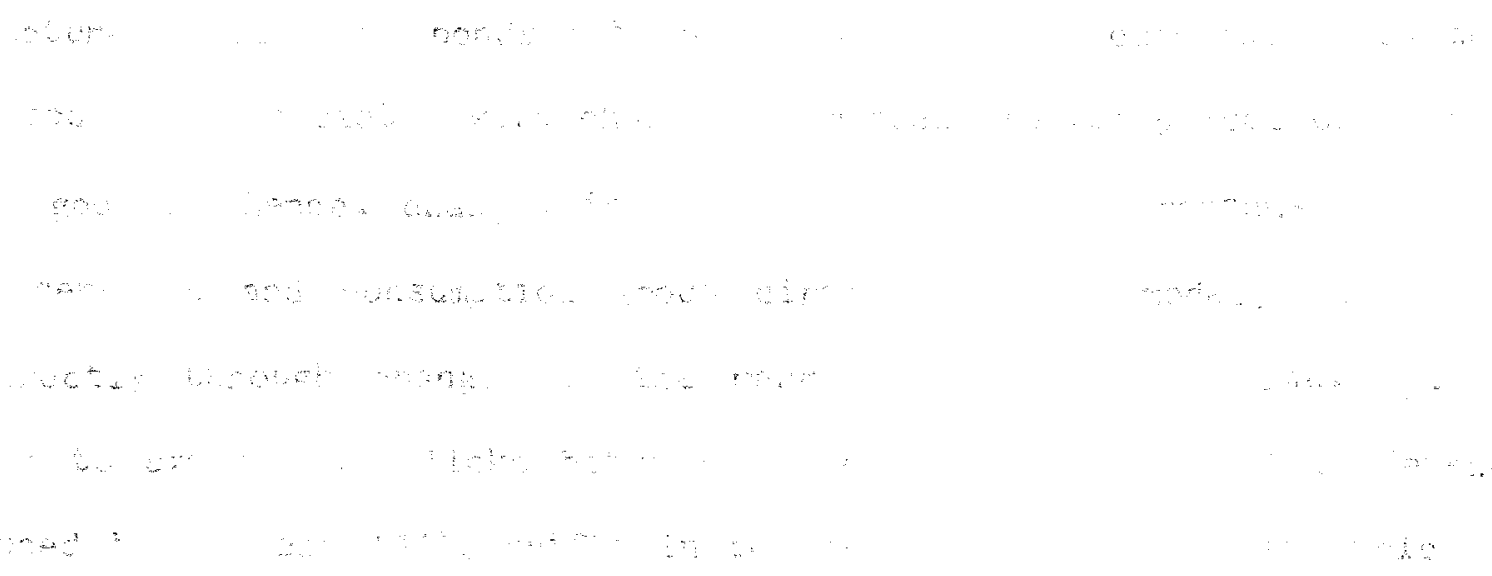

ant....

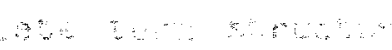

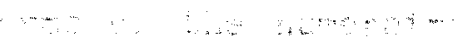

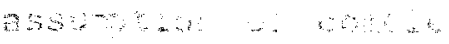

$\sec a+a$

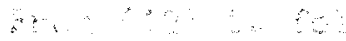




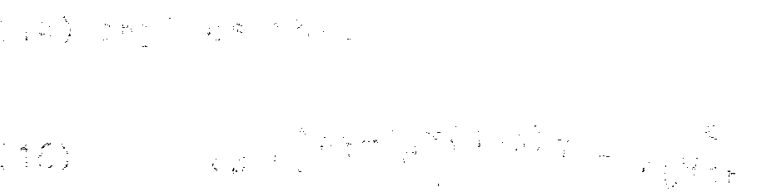

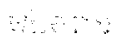

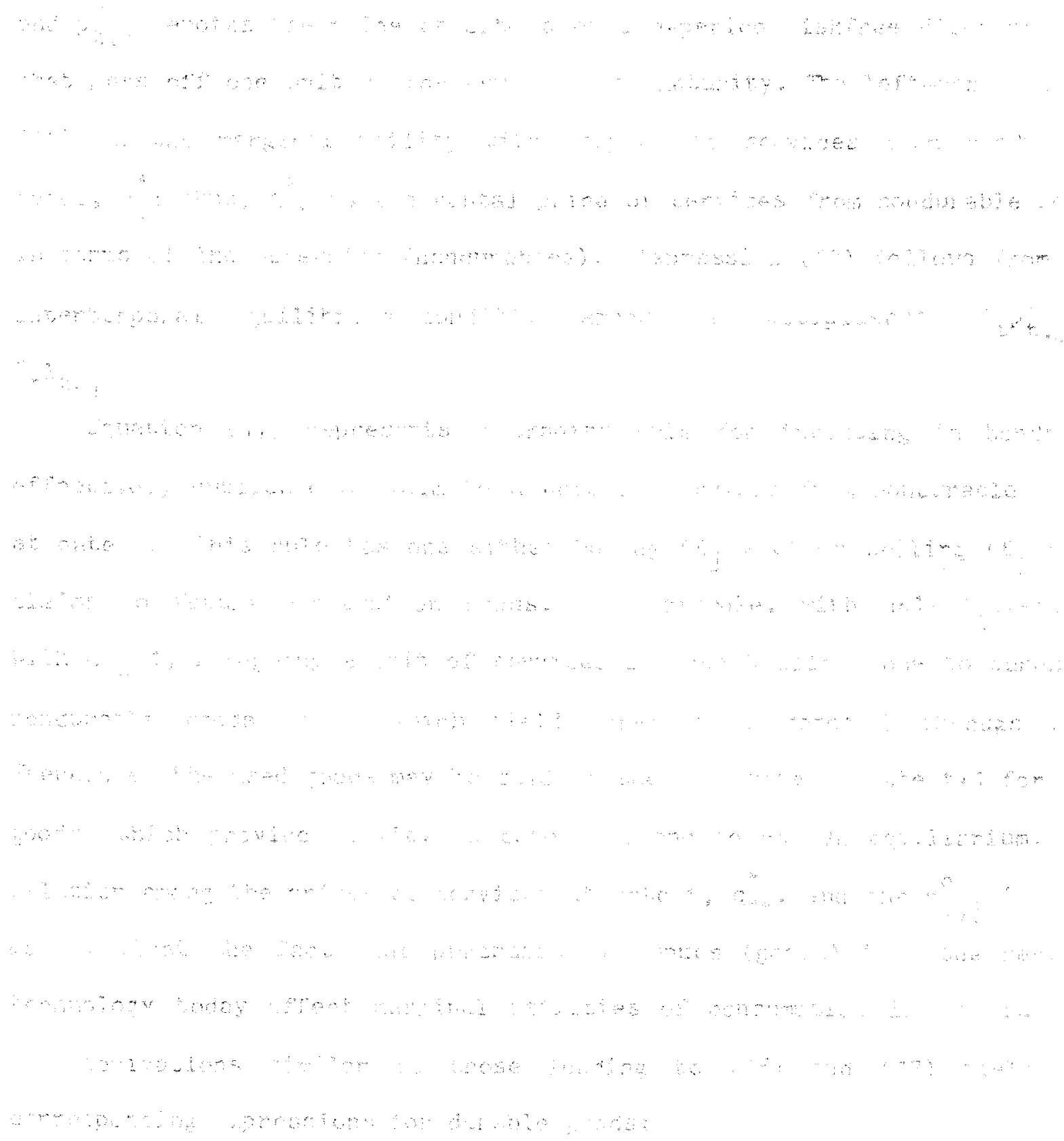




$$
(1-\delta) B^{t} c_{t}^{* \delta} \gamma_{d}^{*}(1-\delta) \gamma-1=\lambda_{t} q^{*}
$$

$$
q_{2 t}^{*}=\frac{1}{\theta}\left[p_{d t}-(1-\theta) p_{t, 1}^{d}\right]
$$

where the left-hand-side of (18) is the marginal utility with respect to services from durable goods, $q_{2 t}^{*}$ is the rental price of services from durable goods, and $p_{t, 1}^{d}=E_{t}\left[p_{d t+1} \lambda_{t+1} / \lambda_{t}\right]$ is the price of a bond that pays off one unit of durable goods at $t+1$. The interpretation of the rental price relation (19) is similar to that of (17). The relatively simple relation (19) arises because the price of a claim to a unit of durable goods for one period is the price of a unit of $d_{t}$ less the present value of the price at date $t+1$ of a claim to the remaining stream of services from date $t+1$ onward yielded by the good. A claim to a unit of durable goods for one period contributes $\theta$ to a unit of services from durable goods at date $t$, so the value of a unit of services, $q_{2 t}^{*}$, equals $1 / \theta$ times the value of a one period claim to a unit of durable goods.

Solving the system of equations $(16)$ and (18) for $c_{t}^{*}$ and $d_{t}^{*}$ yields a version of the dynamic "demand" equations discussed by Eichenbaum and Hansen (1984):

(20)

$$
\left.c_{t}^{*}=\lambda_{t}^{1 /(\gamma-1)}\left\{q_{1 t}^{*} /\left(\delta B^{t}\right)\right\}^{[1-(1-\delta) \gamma] /(\gamma-1)}\left\{q_{2 t}^{*} /(1-\delta) B{ }^{t}\right)\right\}(1-\delta) \gamma /(\gamma-1)
$$

$$
d_{t}^{*}=\lambda_{t}^{1 /(\gamma-1)}\left\{q_{1 t}^{*} /\left(\delta \beta{ }^{t}\right)\right\}^{\delta \gamma /(\gamma-1)}\left\{q_{2 t}^{*} /\left((1-\delta) B^{t}\right)\right\}^{[1-\delta \gamma] /(\gamma-1)}
$$

The demands for services given in (20) are functions of only $\lambda_{t}$ and the contemporaneolis service prices $q_{1 t}^{*}$ and $q_{2 t}^{*}$, because preferences are 
time-separable in service flows. However, the service prices $q_{1 t}^{*}$ and $q_{2 t}^{*}$ are linear combinations of the prices of discount bonds with payoffs denominated in goods and, therefore, changes in these bond prices will in general affect demands for both goods directly as well as indirectly through $\lambda_{t}$. It is these good-denominated bond prices that have been considered in previous consumption-based, intertemporal asset pricing models.

For the special case with $m=0$ in $(9), c_{t}=c_{t}^{*} q_{1 t}^{*}=1$, and preferences are time-separable along the nondurable goods dimension. Nevertheless, changes in bond prices still have direct effects on the demands for both goods through $q_{2 t}^{*}$. If, in addition to $m=0$, preferences are logarithmic $(r=0)$, then $c_{t}$ is proportional to $\lambda_{t}^{-1}[$ see $(16)]$ and focusing on (12) alone leads to a special case of the time-separable model of $c_{t}$ and returns tested in section two. Thus, only if $m=0$ and $r=0$ will the effects of changes in bond prices on $c_{t}$ be restricted to the indirect effects on the marginal utility of wealth. Changes in interest rates affect $d_{t}$ directly for all admissible values of $\gamma$ and $m$.

While the entire class of constant relative risk averse preferences defined over $c_{t}$ alone is not a special case of (8), our model is consistent with a richer set of dynamic interactions among consumptions and returns than the single-good model of section two. Whether or not our model is consistent with the observed comovements in consumptions and returns is an empirical issue to which we turn next. 
4. The Econometric Model and the Data

An important characteristic of the utility function ( 8 ) combined with the linear technologies (9) and (11) is that, under the assumptions of interior optima, complete contingent claims markets for goods, and invertability of the lag polynomials in (9) and (11), (12) and (13) hold with $c_{t}$ and $d_{t}$ being aggregate per capita variables (Eichenbaum and Hansen 1984). The invertability of the lag polynomials is a technical condition that, among other things, implies that the existence of contingent claims markets for goods assures that there are complete markets in services, and vice-versa. Henceforth we shall assume that, given the production technologies of the economy, there is a sufficiently rich set of contingent claims available to investors to assure that (12) and (13) apply to the aggregate quantities used in the empirical analysis.

Expressions (12) and (13) cannot be used directly for empirical analyses since the marginal utility of wealth is unobserved. Let $M U_{c}(t)$ denote the marginal utility of acquiring the numeraire good at date $t$ (i.e., the left-hand-side of (12)). Then an alternative expression involving $M U_{C}(t)$ that does not depend on $\lambda_{t}$ is obtained by substituting the relation $m_{t, n}=M U_{c}(t+n) / M U_{c}(t)$ into $(1)$ :

$$
E_{t}\left[M U_{c}(t)-M U_{c}(t+n) r_{t, n}^{k}\right]=0
$$

From (21) we are able to construct a set of orthogonality conditions like those in (2) upon which estimation and inference can be based.

The marginal utility of wealth can be eliminated from (13) by substituting (12) into (13). The resulting expression still cannot be used directly in our empirical analysis, however, since it depends on the 
infinite order polynomial in the lag operator $\left[1-(1-\theta) B L^{-1}\right]^{-1}$. Instead, we substitute (12) into (18) to obtain

$$
(1-\delta) B^{t}\left\{c_{t}^{* \delta} \gamma_{d}^{*}(1-\delta) \gamma-1\right\}=E_{t}\left\{\left[1-(1-\theta) L^{-1}\right] p_{d t} M U_{c}(t)\right\} / \theta
$$

The intratemporal relation (22) linking the marginal utility of services from durables and $M_{c}(t)$ involves lag polynomials of finite orders $m$ and one. This relation will also be exploited in estimation and inference.

Throughout this discussion we have abstracted from taxation of income. One consideration that arises when there is taxation is that the prices of securities that span two tax years must reflect the value of the option of taking losses or deferring gains (Constantinides 1983). At a more fundamental level, if there is an income tax, then the relations (21) and (22) will in general not hold. Further, aggregation across consumers is in general not possible in the absence of complete markets for both taxable and nontaxable contingent claims. Here we restrict our comments to the latter case of "doubly complete" markets (Dammon 1983) and abstract from end-of-year tax options in order to assess the implications of taxation for models in which the representative consumer paradigm is applicable. We do allow for the marginal tax rate of the representative investor to vary over time as a function of income. 12

Suppose that the income tax from selling a security at date $t+n$ must be paid at date $t+\tau(\tau \geq n)$, and that at that time the consumer's marginal tax rate for ordinary income is $g_{\tau^{*}}$ Then relation (21), for example, must be modified to 


$$
E_{t}\left[M U_{c}(t)-M U_{c}(t+n) r_{t, n}^{k}+M U_{c}(t+\tau) g_{\tau}\left(r_{t, n}^{k}-1\right)\right]=0
$$

The last term in (23) represents the present value of the loss (gain) from the payment of taxes (tax deduction). This term will vary over time with changes in the consumptions, the marginal tax rate of the consumer, the returns on securities, and the length of time between the date the security is sold and the tax payment date. Consequently, unless $g_{\tau}$ is near zero, or the present values of the gains and losses over the sample period are on average approximately zero, the omission of tax obligations from (21) may affect both the consistency of the estimates and the validity of the inferences. Similar observations potentially apply to expression (3), which with taxes becomes

$$
E_{t}\left[M U_{c}(t+n)\left(r_{t, n}^{k}-r_{t, n}^{j}\right)-M U_{c}(t+\tau) g_{\tau}\left(r_{t, n}^{k}-r_{t, n}^{j}\right)\right]=0 .
$$

When $g_{\tau}$ is known to the investor at the investment date $t$, and $n=\tau$, as would be the case with three-month holding periods and quarterly tax payments, (24) simplifies to

(25) $E_{t}\left[M U_{c}(t+n)\left(r_{t, n}^{k}-r_{t, n}^{j}\right)\right]=0$,

which is equivalent to (3). If the dates $\tau$ and $n$ are nearly the same, then (24) and (25) will be nearly the same. Thus, we expect tests based on (25) to be relatively robust to the presence of an income tax which is consistent with our representative consumer model.

In proceeding with estimation, we shall assume that the decision interval of consumers coincides with the sampling interval of the data, 
which is one month. This assumption permits the use of the published data on consumption, without introducing problems associated with temporal aggregation. However, if decision intervals are much shorter and the time series properties of the consumption rates for this interval are different than the properties of the monthly data, then our estimation and inference procedures may yield incorrect conclusions.

The only ways of circumventing temporal aggregation problems that we are aware of is to impose strong distributional assumptions on the series or restrict preferences to be of a very special form. For the reasons given in section two, we choose not to impose distributional assumptions on any of the variables in the model. One can exploit Rubinstein's (1976) result that, for time-separable utility of the logarithmic form, the intertemporal marginal rate of substitution of consumption $m_{t, l}$ is equal to the reciprocal of the real return on the aggregate wealth portfolio. If the latter return is measured by the value-weighted return on the NYSE, for example, then tests can be conducted without restricting the decision interval or having to use consumption data [see Hansen, Richard, and Singleton (1981) and Brown and Gibbons (1983)]. ${ }^{13}$ Clearly, however, in a model with durable goods, as considered here, the wealth of consumers includes the value of the stock of durable goods. Consequently, all of the measurement problems that affect consumption-based tests will potentially affect tests that exploit Rubinstein's result and which measure wealth correctly.

Suppose the holding-period returns from $K$ investments over $n$ periods are to be used in the econometric analysis. The disturbances in our econometric analysis are constructed from (21) and (22) by substituting from (12) for $M U_{c}(t)$. Specifically, we shall interpret the variables 
(26) $u_{k t} \equiv\left[\left(1+\sum_{j=1}^{m} \alpha_{j} \beta^{j} L^{-j}\right) c_{t}^{* \delta \gamma-1} d_{t}^{*}(1-\delta) \gamma\right.$

$$
\left.-B^{n}\left\{\left(1+\sum_{j=1}^{m} a_{j} B^{j} L^{-j}\right) c_{t+n}^{* \delta \gamma-1} d_{t+n}^{*}(1-\delta) \gamma\right\} r_{t, n}^{k}\right] /\left[c_{t}^{* \delta \gamma-1} d_{t}^{*(1-\delta) \gamma}\right]
$$

(27) $u_{K+1, t}=\left[\delta\left(1-(1-\theta) B L^{-1}\right)\left\{p_{d t}\left(1+\sum_{j=1}^{m} a_{j} B^{j} L^{-1}\right) c_{t}^{* \delta \gamma-1} d_{t}^{*(1-\delta) \gamma}\right\}\right.$

$$
\left.-(1-\delta)(1-\theta)\left\{c_{t}^{* \delta \gamma_{d}}{ }_{t}^{*}(1-\delta) \gamma-1\right\}\right] /\left[c_{t}^{*} \delta \gamma-1 d_{t}^{*}(1-\delta) \gamma_{j}\right]
$$

as the disturbances, since $E_{t} u_{k t}=0, k=1, \ldots, K+1$ ( $\operatorname{kee}(21)$ and (22)). The expressions in (26) and (27) are scaled by $\left[c_{t}^{* \delta \gamma-1} d_{t}^{*}(1-\delta) \gamma\right]$ in order that the disturbances will be strictly stationary processes in the presence of certain types of real growth in purchases of goods. The disturbances $u_{k t}$ and $u_{K+1, t}$ are functions of returns and ratios of the form $c_{t+j}^{*} / c_{t}^{*}, d_{t+j}^{*} / d_{t}^{*}$, and $c_{t}^{*} /\left(p_{d t} d_{t}^{*}\right)$. Therefore, if purchases of nondurable and durable goods grow over time (possibly at different rates) according to geometric trends, and the returns and $c_{t}^{*} /\left(p_{d t} d_{t}^{*}\right)$ are stationary, then the disturbances will be strictly stationary stochastic processes. This assumption is maintained throughout our empirical analysis.

Given that the disturbances are stationary stochastic processes, it follows from Wold's decomposition theorem that the disturbances have a moving average representation. Our model of the term structure of interest rates further restricts the covariance structure of the disturbances $u_{k t}$. In particular, the number of nonzero autocovariances of $u_{k t}$ depends on the number of periods, $n$, over which the kth return $(k=1$, .... K) is computed and the degree of non-time-separability of 
preferences. Hansen and Singleton (1982) show that when $\mathrm{n}>1$ and preferences are separable over time the autocovariance function is that of a moving average process of order $n-1$; that is, $E\left(u_{k t} u_{k t-s}\right)=0,|s| \geq$ n. 14 This follows from the observation that with time-separable preferences $u_{k t}$ is not observed by agents until date $t+n$ (i.e., $u_{k t} \varepsilon$ $\left.I_{t+n}\right)$, so $\left(u_{k t}-E_{t} u_{k t}\right)=u_{k t}$ is an $n$-period ahead forecast error. Eichenbaum, Hansen and Singleton (1983) show that when $n=1$ the disturbances in a model with non-time-separable utility have the autocovariance structure of a moving average process of order equal to one less than the maximum number of leads of the decision variables that appear in the estimation equations. In (26) and (27), $(m+1)$ future values of $c_{t}$ and $d_{t}$ appear when $n=1$. Thus, the disturbance $u_{K+1, t}$ follows $a$ $M A(m)$ process $(m+1$ less one). Combining non-time-separable utility with a n-period maturity $(n \geq 1)$ leads to a disturbance, $u_{k t} \varepsilon I_{t+n+m}$. Hence, $E\left[u_{k t} u_{k t+s}\right]=E\left[u_{k t} E_{t+s}\left(u_{k t+s}\right)\right]=0$ for $s \geq n+m$ and the disturbance follows a $M_{A}(n+m-1)$ process, $k=1, \ldots, k$. Similarly, $\left(u_{k t}-u_{\ell t}\right), k \neq \ell$, is a disturbance corresponding to (25) and it will also follow a $M A(n+m-1)$ process. These observations are exploited when constructing estimators of the unknown parameters.

Following Hansen and Singleton (1982), we proceed with estimation by choosing $q_{k}$ dimensional vectors $z_{k t}$ with elements in $I_{t}$ and exploit the fact that $E\left[z_{k t} u_{k t}\right]=0, k=1, \ldots, K+1$. Specifically, let $b_{0}=\left(B, \gamma, \delta, \theta, \alpha_{1}\right.$, $\left.\ldots, a_{m}\right)$ ' denote the parameter vector and let the vector of $K+1$ disturbances be denoted by $u_{t}=\left(u_{1 t} \ldots u_{K+1 t}\right) \cdot$. To simplify notation, let $x_{t+n+m}^{\prime}=\left(\frac{c_{t+1}^{*}}{c_{t}^{*}}, \ldots \frac{c_{t+n+m}^{*}}{c_{t}^{*}}, \frac{d_{t+1}^{*}}{d_{t}^{*}} \ldots, \frac{d_{t+n+m}^{*}}{d_{t}^{*}}, \frac{c_{t}^{*} p_{d t}^{d_{t}^{*}}}{p_{d t+1}}, \frac{p_{d t}}{p_{t, n}}, \ldots, r_{t, n}^{K}\right)$, 
define the function $h$ by the relation $u_{t} \equiv h\left(x_{t+n+m}, b_{0}\right)$, and let

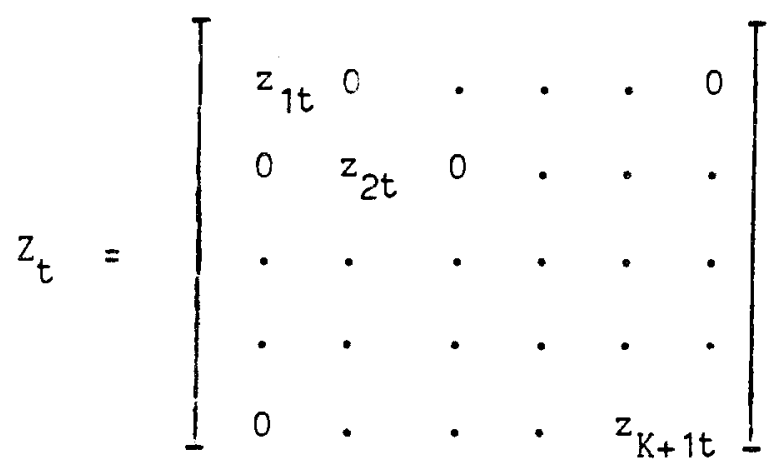

$K+1$

denote an $R$ by $(K+1)$ matrix of instruments, where $R=\sum_{k=1}^{\sum} q_{k}$. Associated with $Z_{t}$ is an $R$ dimensional vector of population anthnzanelity conditions,

$$
g_{0}\left(b_{0}\right)=E\left[z_{t} h\left(x_{t+n+m}, b_{0}\right)\right]=0 .
$$

Treating $g_{0}(b)$ as a function of $b \varepsilon \Omega \subset R^{m+4}$, where $\Omega$ is the admissible parameter space, the method of moments estimator of $g_{0}(b)$ is given by

$$
g_{T}(b)=\frac{1}{T} \sum_{t=1}^{T} z_{t} h\left(x_{t+n+m}, b\right) .
$$

The function $g_{T}(b)$ can be constructed from the sample information $\left\{\left(x_{t+n+m}, z_{1 t}, \ldots, z_{K+1, t}\right), t=1, \ldots, T\right\}$. Assuming $g_{T}(\cdot)$ is a continuous function of $b$, a consistent estimator of $b_{0}$ can be constructed by minimizing a quadratic form in $g_{T}(b)$ by choice of $b \varepsilon \Omega_{\text {. Hansen (1982) }}$ shows that the optimal estimator of $b_{0}$ is obtained by minimizing the criterion function

$$
J_{T}(b)=g_{T}(b) \cdot S_{T}^{-1} g_{T}(b),
$$


where $S_{T}$ is a consistent estimator of

$$
S_{0}=\sum_{\ell=-\infty}^{\infty} E\left[z_{t} u_{t} u_{t-\ell}^{\prime} z_{t-\ell}^{\prime}\right] .
$$

This expression for $S_{0}$ can be simplified in our case because the matrix of instruments is predetermined with $z_{t} \in I_{t}$ and, therefore, the process $\left\{z_{t} u_{t}: t=-\infty, \ldots, \infty\right\}$ inherits the autocovariance structure of $\left\{u_{t}\right\}$. That is, $E\left[z_{t} u_{t} u_{t-l}^{\prime} z_{t-l}^{\prime}\right]=0$ for $\mid \ell ! \geq n+m$, so $\left\{z_{t} u_{t}\right\}$ has the autocovariance structure of an $M A(n+m-1)$ process. Hence, the theoretical model of the term structure implies that

$$
S_{0}=\sum_{\ell=-(n+m-1)}^{n+m-1} E\left[z_{t} u_{t} u_{t-\ell}^{\prime} z_{t-\ell}^{\prime}\right] .
$$

If, as in our empirical analysis, $n \geq m$, then the last $q_{K+1}$ rows and columns of the matrices $E\left[z_{t} u_{t} u_{t-\ell}^{\prime} z_{t-\ell}^{\prime}\right]$ are zero for $\ell>m$, since $u_{K+1, t}$ follows a moving average process of order $m$. These zero restrictions are imposed in the estimation a $S_{0}$.

The optimality of the estimator obtained by minimizing the criterion function, $J_{T}(b)$, requires a consistent estimator of the weighting matrix. $s_{0}^{-1}$, which depends on $b_{0}$. Hence, the estimation procedure requires two steps. First, the identity matrix is substituted for $S_{T}^{-1}$ in the criterion function to obtain initial estimates of the parameters. These estimates are used to construct estimates of the disturbances, which in turn are used to construct the estimator of $S_{0}$ proposed by Hansen (1982) and Hansen and Singleton (1982). The criterion function with the resulting estimate of the weighting matrix, $S_{T}^{-1}$, is then minimized to obtain the optimal estimates of the parameters. In practice, we repeated the last step using 
a revised estimate of $S_{T}^{-1}$ calculated using the parameter estimates at convergence from step two. This assured that the final parameter estimates were not sensitive to the estimate of the weighting matrix.

The empirical specification of our model requires making an assumption about the timing of agents decisions within each month. The real return, $r_{t, n}^{k}$, is computed using the price at the end of month $t$ and the real payoff from the security at the end of month $t+n$. Consumption data measured at the end of month $t$ represent purchases during month $t$. We assume that consumers know the payoffs from securities at the end of month $t$ when making their purchase decisions for month $t$ or, equivalently, that they make their purchase decisions at the end of month $t$. If instead consumers were assumed to make their decisions at the beginning of the month, then they would be able to use $c_{t}$ to predict returns over month $t$. Hence, our assumption about the timing of agents purchase decisions represents a conservative assumption with respect to consumers' information set.

The sample period for the empirical analysis is January 1959 through December 1978. Several considerations influenced this choice. Monthly data on consumptions are available only after January 1959. The use of monthly data allows us to get closer to point to point sampling over a three month holding period than quarterly data. More recent observations on returns are not considered, because of the well known change in operating procedures by the Federal Reserve in October, 1979.

Monthly data on real purchases of nondurables plus services and real purchases of durable goods were obtained from the CITIBASE data tape. These series were defiated by the monthly population series published by the Bureau of Census in order to obtain the per capita real series $\left\{c_{t}\right\}$ 
and $\left\{d_{t}\right\}$. The service flow series $\left\{c_{t}^{*}\right\}$ was then constructed endogenously using equation (9). We used equation (11) to compute the service flow series $\left\{d_{t}^{*}\right\}$ endogenously as a function of the initial stock of durable goods and the current and past purchases of durable goods. The initial value of the stock of durable goods was set at the net value in December of the stock of durables computed by Musgrave (1979). ${ }^{15}$ Then equation (10) was used to construct the real per capita series $\left\{k_{t}\right\}$. The price of durable goods relative to nondurables plus services was computed by dividing the implicit price deflator for durables by the deflator for nondurables plus services. The returns on one-month Treasury bills are taken from Ibbotson and Sinquefield (1982), and the returns on three- and six-month bills are those constructed by Huizinga and Mishkin (1983) from the CRSP government bond tape. Real returns were calculated by dividing the numerator and denominator of the nominal returns by the value of the implicit price deflator for nondurabies plus services (the numeraire) for the month corresponding to the maturity and purchase, respectively, of the security. 
5. Empirical Results

The results from estimating the model with a single return $(K=1)$ are displayed in Table II. Initially, we assume that $m=1$ so that $c_{t}^{*}=c_{t}+$ $a c_{t-1}$. The instrument vector, $z_{1 t}$, associated with the disturbance $u_{1 t}$ in (26) included the constant unity, the lagged value of the real rate of return on the security, and the first lagged value of the growth rates of real per capita consumption of nondurables plus services, real per capita purchases of durable goods, and the relative price of durables:

$$
z_{1 t}^{\prime}=\left(1, r_{t-n, n}^{1}-1, \frac{d_{t}}{d_{t-1}}-1, \frac{c_{t}}{c_{t-1}}-1, \frac{p_{d t}}{p_{d t-1}}-1\right) .
$$

To construct the intratemporal orthogonality conditions associated with the disturbance $u_{2 t}$ in (27), we set $z_{2 t}$ equal to $z_{1 t}$.

In addition to the parameter estimates and estimates of their respective standard errors, we report a statistic for testing the validity of the overidentifying restrictions implied by the model. Five linear combinations of the $R$ sample orthogonality conditions are set to zero in estimating the $5 \times 1$ vector $b_{0}$. There are an additional $R-5$ independent linear combinations of $\mathrm{g}_{\mathrm{T}}\left(\mathrm{b}_{\mathrm{T}}\right)$ that are not set to zero in estimation, but that should be close to zero if the model is valid. Hansen (1982) shows that a test of the null hypothesis that the population counterparts of these R-5 linear combinations of $g_{T}\left(b_{T}\right)$ are zero can be based on the product of the number of time series observations and the minimized value of the criterion function. This statistic is distributed asymptotically as a chi-square with $R-5$ degrees of freedom (DF) under the null hypothesis. 
The computed values of this statistic for the single-return runs $(R=10)$ are displayed in column 7 of Table II. The probability values (1-significance level) of the statistics are given in parentheses. None of these statistics provide strong evidence against the model, although there is substantially more evidence against the model when the return used in estimation is the one-month return on a one-month Treasury bill (TBILL1). One interpretation of the latter finding is that the reliance on information that is gathered at quarterly intervals in constructing the monthly data distorts the time series properties of the monthly, relative to the quarterly, series. ${ }^{16}$ To the extent this is the case, the results for the three-month returns, which are based on monthly data point-sampled at quarterly intervals, may be more reliable.

The parameter estimates displayed in Table II are qualitatively similar for all of the securities. The point estimates of the concavity parameter, $\gamma$, range from -.1922 for TBILL1 to -1.0209 for the three-month return from rolling over three one-month bills (ROLL 1 ). The estimates of the lag for consumption of nondurables, $\alpha$, are economically plausible. In all cases, the $\hat{a}^{\prime}$ s are positive and, except for ROLL1, are at least twice as large as their respective standard errors. The estimates of the allocation parameter $\delta$ are also plausible. The estimates of the discount factor, $B$, are, however, slightly greater than unity. This could be a consequence of the occurance of negative ex post real returns in terms of the numeraire during the estimation period. Values of $\beta$ less than unity are within two standard errors of the point estimates. Finally, the estimates of the proportion of the capital stock consumed each month, $\hat{\theta}$, range from .0027 per month (3\% per year) to .0082 per month ( $10 \%$ per year). This fairly wide range of depreciation rates is symptomatic of the imprecision with which $\theta$ is estimated. 
There are two differences between the models discussed in sections two and three that may explain the large values of the test statistics displayed in Table I relative to those in Table II for the three-month return on a three-month Treasury bill (TBILL3). First, the utility function (8) is a nonseparable function of the acquisitions of nondurable and durable goods at each date (i.e., the cross-partials of (8) with respect to $c$ and $d$ are nonzero). Second, the model described in section three incorporates the non-time-separable service technology (9) for nondurable goods. To determine which difference best accounts for the better fit of the model with utility function ( 8 ), we estimated a version of a one-good model with the period utility function $\left(c_{t}^{*}\right)^{\gamma / \gamma}$, where $c_{t}^{*}$ is given by (9). The chi square statistic with two degrees of freedom is 15.92 with a probability value of .9996 , so again the one-good formulation of the model is not consistent with the data. We conclude that the nonseparability across decision variables at a point in time is an important ingredient in the better fit of our two-good model. In particular, despite the imprecision with which $\gamma$ is estimated, the point estimates of $Y$ along with the comparisons across the alternative models suggest that investors are more risk averse than logarithmic utility $(\gamma=0$, which implies separability across decision variables). At the same time, the estimated value of $a$ is .2923 with a standard error of .063 , so a non-time-separable service technology is common to both models.

Estimates obtained using the three-month returns from two different investment strategies $(K=2)$ are dispiayed in Table III. The column labeled "Returns" should be read as follows. "TEILL3 \& ROLLi" indicates that the estimates were obtained with the disturbance of the equation associated with each of these returns given by (26) with $n=3$ and $r_{t, 3}^{k}$ 
equal to TEILL3 for $k=i$ and ROLL1 for $k=2$. Thus, we are testing simultaneously the restrictions implied by (2) for TBILL3 and for ROLL1. On the other hand, "TBILL3 \& TB6H3-TBILL3" indicates that the first disturbance is given by (26) with $r_{t, 3}^{k}=$ TBILL3 and the second disturbance is given by the difference between the versions of (26) for the three-month holding period return on a six-month Treasury bill (TB6H3) and TBILL3. In this case, we are testing simultaneously restrictions implied by (2) for TBILL3 and restrictions implied by (4) for TB6H3-TBILL3. In all cases the instrument vector associated with the disturbance $u_{\text {it }}$ for the first return listed was $z_{1 t}$ given by $(28)$. When $D F=6(R=11)$ the instrument vector associated with the disturbance for the second return (or the difference between two returns) was $z_{2 t}=\{1\}$; while for $D F=7$ $(R=12), z_{2 t}^{\prime}=\left\{1, r_{t-n, n}^{2}-1\right\} \cdot^{17}$

The parameter estimates are similar to those displayed in Table II, with the exception of the $\hat{\gamma}^{\prime} s$ and $\hat{\alpha}^{\prime} s$. The range of the point estimates of $\gamma$ in Table III is from -1.5038 for TBILL3 \& TB6H3 to -2.6302 for TB6H3 \& ROLL1. These point estimates are suggestive of a higher level of relative risk aversion than those in Table II, although again the estimated standard errors are large. Also, the $\hat{\alpha}$ 's and their respective standard errors are substantially smaller in Table III than the estimates obtained for the three-month returns in Table II.

Perhaps the most notable difference, however, is that all of the test statistics displayed in Table III provide substantial evidence against the model. This result seems particularly striking because, for $D F=6$, the larger test statistics are a consequence of including only one orthogonality condition for the disturbance $u_{2 t}$ associated with the second return. Indeed, adding the lagged value of the second return to $z_{2 t}$ 
(increasing DF from 6 to 7 ) has little incremental effect on the test statistics or the estimated parameters.

From the results displayed in Tables I through III we conclude that there is a vector of admissable parameters for which our model is consistent with the comovements of consumptions and the return on any single security (Table II). Recall that the single-good model with time-separable preferences was not consistent with these aggregate comovements (Table I). At the same time, our model fails to capture the joint behavior of consumptions and any two returns (Table III). In light of the findings for the individual securities, the latter conclusion seems not to be a consequence of our omission of the future tax obligations for the representative agent. For if tax considerations of the type discussed in section four are important, then there should be more evidence against the model in Table II. Furthermore, by comparing rows three and five in" Table III, it can be seen that replacing TB6H3 by TBILL3-TB6H3 has little effect on the test statistics. 18

A second possible explanation for the large test statistic in Table II is that a larger value of $m$ is required to adequately represent the technology for producing services from nondurable goods. We pursued this possibility by setting $\mathrm{m}=2$ and re-estimating the model with TBILL3 \& TB6H3. The estimated value of the coefficient on $c_{t-2}$ in (9), a , was of the order $10^{-4}$, and the probability value of the test statistic was approximately unity. Thus, increasing the number of lags in the service technology for nondurable goods does not alter the conclusions drawn from Tabie II. 19

We turn next to an examination of the counterparts of the unconditional covariance restrictions in (7) for the model with 
non-time-separable utility. From equation (21) and the definition of a covariance, it follows that

(29) $E\left[r_{t, 3}^{k}\right]-E\left[M U_{c}^{*}(t) z_{t}\right] / E\left[M U_{c}^{*}(t+3) z_{t}\right]=$

$$
-\operatorname{Cov}\left[r_{t, 3}^{k}, M U_{c}^{*}(t+3) z_{t}\right] / E\left[M U_{c}^{*}(t+3) z_{t}\right]
$$

where $\operatorname{MU}_{c}^{*}(t+l) \equiv \operatorname{MU}_{c}(t+l) /\left[c_{t}^{* \delta \gamma-1} d_{t}^{*}(1-\delta) \gamma_{1}\right], l \geq 0$. The restrictions are expressed in terms of $\mathrm{MU}_{c}^{*}(t+l)$ instead of $\mathrm{MU}_{c}(t+l)$, since it is the former variable which is used in estimation and assumed to be a strictly stationary stochastic process. Also, marginal utilities are studied instead of the marginal rates of substitution that appear in (7), because with non-separable preferences the marginal rates of substitutions are ratios of agents' marginal utilities which involve conditional expectations that are unobserved to the econometrician. Finally, we have chosen to study (29) with $z_{t}=1$, since this instrument led to a substantial increase in the test statistics in Table III over those in Table II.

We calculated the sample versions of the left (ER) and right (RP) hand sides of (29) using the estimated parameter values from the TBILL3 \& TB6H3 run with $\mathrm{DF}=6$ in Table III, and by replacing population moments by their sample counterparts. Estimates of $E R$ and $R P$ were calculated for several values of $r$, holding the other parameters fixed at their estimated values. These results are displayed in Table IV. Notice, first of ali, that for the value of $\gamma$ from Table III $(\hat{\gamma}=-1.581)$ the estimates of ER are approximately two orders of magnitude larger than the corresponding estimates of RP. Nevertheless, for each return, $|\hat{E} R-\hat{R P}|$ is zero for 
values of $Y$ within the range $(-1.58,-2)$, which is well inside a one standard-derivation confidence interval about $\hat{\gamma}$. This finding is consistent with the small probability values of the test statistics displayed in Table II -- the restriction (29) for each return is nearly satisfied at the point estimates. 20

The latter result warrants further discussion, since much attention has been given to the role of risk aversion in explaining the temporal and relative behavior of asset returns. Increasing $|\gamma|$ leads to an increase in the volatility of $\mathrm{MU}_{\mathrm{c}}^{*}(t+3)$ and, therefore, in a perfect certainty environment a large value of $|r|$ may be required to reconcile the smooth behavior of consumptions with the relative choppy behavior of returns over time [see e.g., Grossman and Shiller, (1981)]. In an uncertain environment, however, what is relevant for explaining average differences between returns is the covariance of returns with $\mathrm{MU}_{c}^{*}(t+3)$ relative to $E\left[M U_{c}^{*}(t+3)\right]$. Values of $\gamma$ between -1.581 and -2 generate sufficient variability in $\mathrm{MU}_{\mathrm{c}}^{*}(t+3)$ and the appropriate covariability of $\mathrm{MU}_{\mathrm{c}}^{*}(t+3)$ and the returns to satisfy the restrictions in (29) for individual securities. This was not the case with the single-good model discussed in section two. Much stronger evidence against our model is obtained from the two-return runs, because these runs impose restrictions on the relative values of the risk premia for TBILL3 and $\mathrm{TB} 6 \mathrm{H} 3$ that are not imposed in the single-return runs. Specifically, forming the difference of the versions of (29) for two returns gives

(30) $E\left[r_{t, 3}^{1}\right]-E\left[r_{t, 3}^{2}\right]=-\operatorname{Cov}\left[r_{t, 3}^{1}-r_{t, 3}^{2}, M U_{c}^{*}(t+3)\right] / E\left[M U_{c}^{*}(t+3)\right]$. 
The nuli hypothesis that the restriction ( 30 ) holds is implicitly being tested when the model is estimated using both TBILL3 and TB6H3. The sample versions of the left $\left(E R_{1}-E R_{2}\right)$ and right $\left(R P_{1}-R P_{2}\right)$ hand sides of (30) are reported in column six of Table IV. At the estimated value of $r$ $(-1.581), \hat{E R}_{1}-\hat{E} R_{2}$ is three orders of magnitude larger than $\hat{R P}_{1}-\hat{R P}_{2}$, a finding which is reminiscent of the result in Table I for TBILL3. Moreover, increasing $|\gamma|$ has a negligible effect on the difference between $\hat{E} R_{1}-\hat{E} R_{2}$ and $\hat{R P}_{1}-\hat{R P}_{2}$. Over a wide range of values of the risk aversion parameter, the relative values of the sample covariances of $M U_{C}^{*}(t+3)$ and the returns are not consistent with the relative values of the sample mean returns. In this sense, the model fails to capture the relative risk structure of the two securities.

For the non-time-separable specification of preferences $(8), \hat{R P}_{1}-\hat{R P}_{2}$ is not a monotonic function of $r$. The difference between $E \hat{R}_{1}-E \hat{R}_{2}$ and $\hat{R P}_{1}-R \hat{P}_{2}$ is minimized among the $\gamma^{\prime}$ s considered at $\gamma=-25$. Nevertheless; from Table IV it is clear why the estimated value of $\gamma$ is not closer to -25. Increasing $|\gamma|$ leads to an increase in $E\left[M U_{c}^{*}(t)\right] / E\left[M U_{c}^{*}(t+3)\right]$, since acquisitions of nondurable and durable goods evidenced positive growth during the sample period. 21 Because $E\left[M_{c}^{*}(t)\right] / E\left[M U_{c}^{*}(t+3)\right]$ increases substantially relative to the increase in $\hat{\mathrm{RP}}$, the required level of the average return $E\left[r_{t, n}^{k}\right]$ increases rapidly with increases in $|Y|$ so that the signs of $\hat{E R}$ and $\hat{R P}$ are not consistent with the theory for values of $|\gamma|>$ 2. The weight given by the criterion function to making $|\hat{E R}-\hat{R P}|$ small in estimating the parameters prevents $\hat{\gamma}$ from approaching -25 .

The final experiment we conducted was to let $\alpha$ range between 0 and .8, holding all of the other parameters (including $\gamma$ ) fixed at their estimated values. Estimates of ER and RP for TBILL3, calculated using the 
growth rate of purchases of nondurable goods for $z_{t}$ in (29), are displayed in Tabie $V$. At the estimated value of a for the TBILL3 run reported in Table II $(\hat{\alpha}=.5384), \hat{E R}$ and $\hat{R P}$ are an order of magnitude apart, but $|E \hat{R}-\hat{R} \hat{P}|$ is zero at a value for a between .2 and .4 , which is within two-standard errors of $\hat{\alpha}$. Values of $\hat{E R}$ and $\hat{R P}$ for TEILL3 computed using the point estimates reported in Table III for the TBILL3 \& TB6H3 run with $D F=6$ are also displayed in Table V. For the parameters from the TBILL3 \& TR6H3 run, the values of $\hat{E R}$ and $\hat{R P}$ for TBILL3 do not have the same sign at the estimated value of $\alpha(\hat{\alpha}=.2891)$. Also, $\mid \hat{E R}-\hat{R P I}$ decreases with increasing $\alpha$, a pattern which is consistent with the estimate of $\alpha$ of .5383 obtained when only TBILL3 is studied. The relatively large value of $|\hat{E R}-\hat{R P}|$ at $\hat{\alpha}=.2891$ from the TBILL3 \& TB6H3 run, compared to the value of $|E \hat{R}-\hat{R}|$ at $\hat{\alpha}=.5384$ from the TBILL3 run, reflects the tradeoffs involved in attempting to set different sets of sample orthogonality conditions to zero in estimating the parameters. In both cases, the largest difference between $\hat{E R}$ and $\hat{R P}$ occurs at $a=0$, which is the value of $\alpha$ that corresponds to time-separable utility along the nondurable goods dimension. 
6. Concluding Remarks

In this paper we have argued that specifying utility to be a nonseparable function of the purchases of nondurable and durable goods at each date allows for much richer term structure relations than models with separable preferences. The empirical findings support this view in that our model with nonseparable preferences is consistent with the observed comovements of individual real returns on short-term Treasury bills and aggregate consumptions. More precisely, for plausible values of the parameters governing preferences, both the variability of marginal utilities, and their covariability with returns, were consistent with the average values of the ex post real returns. In contrast, the consumption risk inherent in previous models with time-separable utility functions defined over a single decision variable is not consistent with average real returns on Treasury bills.

When the implied restrictions on the real returns from following two different investment strategies with Treasury bills were studied simultaneously, substantial evidence against the model with nonseparable utility was obtained. Thus, this model is not consistent with observed comovements of real returns on alternative investment strategies. In the light of the pattern of parameter estimates and test statistics, considerations associated with taxation of income appear not to be the explanation for this finding. A potential explanation for the large test statistics emerges from examining the restriction that the difference between the mean returns from two investments be proportional to the differences between the covariances of the marginal utility of consumption and each return. The magnitudes of the covariances are not consistent with the relative values of the sample means of the returns and in this 
sense the model does not capture the relative riskiness of the two investment strategies. Moreover, increasing relative risk aversion, even to extreme values, is virtually of no value in attempting to satisfy these moment restrictions. This is the case even though the variability of ex post marginal utilities increases with increases in $|r|$.

Previously, Hansen and Singleton (1982) found that a model with a time-separable utility function defined over purchases of nondurable goods was not consistent with the comovements of returns on stocks and Treasury bills. Our results suggest that incorporating durable goods and non-time-separable technologies for producing services from goods [at least as in (8)-(11) ] is also not sufficient to reconcile representative agent, asset pricing models with the observed comovements of security returns. What is needed to explain the relative risk structure of securities is a model in which the marginal utilities have very different covariance properties with returns than those that have been studied to date. Modifications of representative agent models to incorporate money through the imposition of a cash-in-advance constraint (e.g., Lucas 1983) is one way of affecting the time series properties of marginal utilities. However, the analysis in Singleton (1984) suggests that such a modification to our nonseparable model does not improve the fit for real Treasury bill returns. Alternative incomplete market structures for contingent claims that rationalize a monetary economy with an active policy authority, or models in which agents are differentially informed, may be required to explain the temporal behavior of Treasury bill returns. Such models may not lead to testable restrictions expressed in terms of aggregate consumptions or wealth, in which case empirical analyses will require disaggregated data. 
Finally, we note that our analysis [Dunn and Singleton (1983)] of returns on stock, long-term government bonds, and GNMA mortgage pass-through securities provided little evidence against a model with a separable utility function. For comparison, we re-estimated our nonseparable model with durable and nondurable goods using the value-weighted return on the New York Stock Exchange from the CRSP tapes and the long-term government bond return series constructed by Ibbotson and Sinquefield (1982). The resulting test statistic provides little evidence against the model $\left[x^{2}(7)=7.75\right]$. Thus, there seems to be an important difference between the ability of representative agent, asset pricing models to capture the comovements among certain "long-term" securities and short-term Treasury bills. This pattern of results also warrants further examination. 
TABLE II

ESTIMATES FOR THE INDIVIDUAL SECURITIES

FOR THE PERIOD JANUARY 1959 TO DECEMBER $1978^{\circ}$

\begin{tabular}{|c|c|c|c|c|c|c|c|}
\hline Returns & $\hat{B}$ & $\hat{\gamma}$ & $\hat{\delta}$ & $1-\hat{\theta}$ & $\hat{a}$ & $x^{2}$ & DF \\
\hline TBILL1 & $\begin{array}{l}1.0024 \\
(.0016)\end{array}$ & $\begin{array}{l}-.1922 \\
(.6706)\end{array}$ & $\begin{array}{l}.9003 \\
(.0642)\end{array}$ & $\begin{array}{c}.9918 \\
(.0129)\end{array}$ & $\begin{array}{l}.2664 \\
(.0542)\end{array}$ & $\begin{array}{r}11.4885 \\
(.9575)\end{array}$ & 5 \\
\hline ROLL1 & $\begin{array}{l}1.0040 \\
(.0032)\end{array}$ & $\begin{array}{l}-1.0209 \\
(1.3028)\end{array}$ & $\begin{array}{c}.9177 \\
(.2170)\end{array}$ & $\begin{array}{l}.9952 \\
(.0291)\end{array}$ & $\begin{array}{l}.5556 \\
(.2318)\end{array}$ & $\begin{array}{l}6.6775 \\
(.7542)\end{array}$ & 5 \\
\hline TBILL3 & $\begin{array}{l}1.0038 \\
(.0032)\end{array}$ & $\begin{array}{c}-.9661 \\
(1.2726)\end{array}$ & $\begin{array}{c}.9207 \\
(.1805)\end{array}$ & $\begin{array}{l}.9958 \\
(.0228)\end{array}$ & $\begin{array}{c}.5384 \\
(.2147)\end{array}$ & $\begin{array}{l}5.5835 \\
(.6511)\end{array}$ & 5 \\
\hline TB6H3 & $\begin{array}{l}1.0031 \\
(.0027)\end{array}$ & $\begin{array}{c}-.7766 \\
(1.0945)\end{array}$ & $\begin{array}{c}.9303 \\
(.1246)\end{array}$ & $\begin{array}{l}.9973 \\
(.0131)\end{array}$ & $\begin{array}{c}.5337 \\
(.2050)\end{array}$ & $\begin{array}{l}4.6953 \\
(.5458)\end{array}$ & 5 \\
\hline
\end{tabular}

a. TBILL1 = one month return on a one month Treasury bill, ROLL1 = three month return from rolling over one month Treasury bills, TBILL3 = three month return on a three month Treasury bill return, $\mathrm{TB} 6 \mathrm{H} 3=$ three month return on a six month Treasury bill. Standard errors of the parameter estimates and probability values ( 1 - significance levels) of the test statistics are given in parentheses. 
TABLE III

ESTIMATES FOR COMBINATIONS OF SECURITES

FOR THE PERIOD JANUARY 1959 TO DECEMBER $1978^{\circ}$

\begin{tabular}{|c|c|c|c|c|c|c|c|}
\hline Returns & $\hat{B}$ & $\hat{r}$ & $\hat{\delta}$ & $1-\hat{\theta}$ & $\hat{\alpha}_{1}$ & $x^{2}$ & $D F$ \\
\hline $\begin{array}{l}\text { TBILL3 \& } \\
\text { ROLL } 1\end{array}$ & $\begin{array}{l}1.0061 \\
(.0041)\end{array}$ & $\begin{array}{l}-1.8915 \\
(1.9644)\end{array}$ & $\begin{array}{l}.8611 \\
(.0080)\end{array}$ & $\begin{array}{l}.9670 \\
(.0174)\end{array}$ & $\begin{array}{l}.2364 \\
(.0561)\end{array}$ & $\begin{array}{l}56.0261 \\
(1.0000)\end{array}$ & 6 \\
\hline $\begin{array}{l}\text { TBILL3 \& } \\
\text { ROLL } 1\end{array}$ & $\begin{array}{l}1.0074 \\
(.0051)\end{array}$ & $\begin{array}{l}-2.3507 \\
(2.2195)\end{array}$ & $\begin{array}{l}.8785 \\
. .0193)\end{array}$ & $\begin{array}{l}.9844 \\
(.0086)\end{array}$ & $\begin{array}{l}.2306 \\
(.0751)\end{array}$ & $\begin{array}{l}59.6203 \\
(1.0000)\end{array}$ & 7 \\
\hline $\begin{array}{l}\text { TBILL3 \& } \\
\text { TB6H3 }\end{array}$ & $\begin{array}{l}1.0058 \\
(.0040)\end{array}$ & $\begin{array}{l}-1.5811 \\
(1.6974)\end{array}$ & $\begin{array}{l}.9008 \\
(.1115)\end{array}$ & $\begin{array}{l}.9921 \\
(.0220)\end{array}$ & $\begin{array}{l}.2891 \\
(.0719)\end{array}$ & $\begin{array}{l}33.7261 \\
(1.0000)\end{array}$ & 6 \\
\hline $\begin{array}{l}\text { TBILL3 \& } \\
\text { TB6H3 }\end{array}$ & $\begin{array}{l}1.0054 \\
(.0037)\end{array}$ & $\begin{array}{l}-1.5038 \\
(1.6251)\end{array}$ & $\begin{array}{l}.9043 \\
(.1528)\end{array}$ & $\begin{array}{l}.9930 \\
(.0273)\end{array}$ & $\begin{array}{l}.2964 \\
(.0712)\end{array}$ & $\begin{array}{l}34.4419 \\
(1.0000)\end{array}$ & 7 \\
\hline $\begin{array}{l}\text { TBILL3 \& } \\
\text { TB6H3 - } \\
\text { TBILL3 }\end{array}$ & $\begin{array}{l}1.0057 \\
(.0039)\end{array}$ & $\begin{array}{l}-1.5349 \\
(1.6721)\end{array}$ & $\begin{array}{l}.9019 \\
(.1221)\end{array}$ & $\begin{array}{l}.9923 \\
(.0235)\end{array}$ & $\begin{array}{l}.2986 \\
(.0711)\end{array}$ & $\begin{array}{l}33.6548 \\
(1.0000)\end{array}$ & 6 \\
\hline $\begin{array}{c}\text { TB6H3 \& } \\
\text { ROLL } 1\end{array}$ & $\begin{array}{l}1.0078 \\
(.0048)\end{array}$ & $\begin{array}{l}-2.6302 \\
(2.1708)\end{array}$ & $\begin{array}{l}.8689 \\
(.0136)\end{array}$ & $\begin{array}{l}.9788 \\
(.0111)\end{array}$ & $\begin{array}{l}.2870 \\
(.0521)\end{array}$ & $\begin{array}{l}41.0502 \\
(1.0000)\end{array}$ & 6 \\
\hline $\begin{array}{l}\text { TBILL3 \& } \\
\text { TB6H3 - } \\
\text { ROLL1 }\end{array}$ & $\begin{array}{l}1.0059 \\
(.0040)\end{array}$ & $\begin{array}{l}-1.5833 \\
(1.6934)\end{array}$ & $\begin{array}{l}.8934 \\
(.0582)\end{array}$ & $\begin{array}{l}.9900 \\
(.0145)\end{array}$ & $\begin{array}{l}.2997 \\
(.0693)\end{array}$ & $\begin{array}{l}41.3449 \\
(1.0000)\end{array}$ & 6 \\
\hline
\end{tabular}

\footnotetext{
a. TBILL1 = one month return on a one month Treasury bill, ROLL1 = three month return from rolling over one month Treasury bilis, TBILL3 = three month return on a three month Treasury bill, TB6H3 = three month return on a six month Treasury bill. Standard errors of the parameter estimates and probability values (1-significance levels) of the test statistics are given in parentheses.
} 


\section{TABLE IV}

Estimates of ER and RP for TBILL3 and TB6H3

$\begin{array}{lccccc}r & E_{1}{ }^{T B I L L 3} & R_{1} & R_{2} R_{2} & R_{2} & \left(E R_{1}-E R_{2}\right)-\left(R_{1}-R_{2}\right) \\ 0.0 & 1.270-02 & 6.898-06 & 1.393-02 & 7.154-06 & -1.2360-03 \\ -1.581 & 1.688-03 & 1.750-05 & 2.924-03 & 1.791-05 & -1.2358-03 \\ -2 . & -1.239-03 & 2.032-05 & -3.167-06 & 2.077-05 & -1.2358-03 \\ -3 . & -8.243-03 & 2.708-05 & -7.007-03 & 2.762-05 & -1.2357-03 \\ -4= & -1.527-02 & 3.386-05 & -1.403-02 & 3.449-05 & -1.2356-03 \\ -8 . & -4.361-02 & 6.128-05 & -4.238-02 & 6.223-05 & -1.2353-03 \\ -12 . & -7.232-02 & 8.916-05 & -7.109-02 & 9.039-05 & -1.2350-03 \\ -16 . & -.1014 & 1.175-04 & -.1001 & 1.190-04 & -1.2348-03 \\ -25 . & -. .1680 & 1.831-04 & -.1667 & 1.847-04 & -1.2346-03 \\ -50 . & -. .3605 & 3.788-04 & -.3593 & 3.786-04 & -1.2364-03 \\ -100 . & -.7627 & 8.330-04 & -.7615 & 8.143-04 & -1.2549-03\end{array}$


TABLE V

Estimates of ER and RP for TBILL3 Using the Growth Rate of Nondurable Purchases as an Instrument

a

0

.2

.2891

.4

.5384

.6

.8
Parameters from

TBILL3 Run

ER

$4.179-03 \quad-1.127-04$

$9.250-04 \quad-1.147-04$

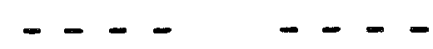

$-5.100-04 \quad-1.150-04$

$-1.164-03 \quad-1.166-04$

$-1.327-03 \quad-1.169-04$

$-1.127-03 \quad-1.175-04$
Parameters from TEILL3 \& TB6H3 Run

ER

RP

$\begin{array}{cc}7.160-03 & -1.092-04 \\ 2.990-03 & -1.118-04 \\ 1.932-03 & -1.126-04 \\ 1.021-03 & -1.135-04 \\ ---- & ---- \\ 9.970-05 & -1.146-04 \\ -2.858-04 & -1.155-04\end{array}$




\section{FOOTNOTES}

${ }^{1}$ Contrary to most studies, Dunn and Singleton (1983) did not find much evidence against a single-good model with time-separable utility using returns on stocks, long-term government bonds, and Ginnie-Mae mortgage pass-through securities. In the conclusion, we comment further on the similarities and differences among the results reported here and those in our earlier study.

2 The following discussion is easily modified for the case of coupon paying bonds.

${ }^{3}$ Sufficient conditions for (1) to obtain in discrete-time are given in Rubinstein (1976), Breeden and Litzenberger (1978), Lucas (1978), and Brock (1980) for models with time-separable preferences. Extensions to models with multiple goods and certain types of non-time-separable preferences are provided in Prescott and Mehra (1980), Kydland and Prescott (1982), and Eichenbaum, Hansen, and Singleton (1983). Continuous-time versions of (1) were deduced by Cox, Ingersoll, and Ross (1978), Ereeden $(1979,1983,1984)$, and Richard and Sundaresen (1981) for models with time-separable utiity.

${ }^{4}$ If $E\left[y_{t} \mid I_{t}\right]=0$, then $E\left[y_{t} z_{t}\right]=0$ for any $z_{t} \varepsilon I_{t}$, since $E\left[y_{t} z_{t}\right]=$ $E\left\{z_{t} E\left[y_{t} \mid I_{t}\right]\right\}=0$. In actual applications, we interpret $I_{t}$ to be the sigma-algebra generated by the current and past histories of all square-integrable random variables observed by agents.

${ }^{5}$ Specifically, using arguments like those in Hansen and Singleton (1983) and Ereeden $(1984)$, let $x_{t}^{\prime}=\left(\log m_{t, n}, \log r_{t, n}^{j}, \log r_{t, n}^{k}\right)$ and suppose that $\left\{x_{t}:-\infty<t<\infty\right\}$ is a normally distributed, stationary stochastic process. Also, let $\psi_{t}$ denote the information set generated by $\left\{x_{s}: s \leq\right.$ $t$. The expectation of (3) conditioned on $\psi_{t}$ is $E\left[m_{t, n} r t_{t, n}^{j} \mid \psi_{t}\right]=$ $E\left[m_{t, n}{ }^{r k} t, n \mid \psi_{t}\right]$. Using the fact that $\log E\left[v_{t+s} \mid \psi_{t}\right]=E\left[\log v_{t+s} \mid \psi_{t}\right]+1 / 2$ $\operatorname{Var}\left[\log v_{t+s} / \psi_{t}\right]$ when the distribution of $v_{t+s}$ conditioned on $\psi_{t}$ is log-normal, we obtain

$$
E\left[\log r_{t, n}^{j} \mid \psi_{t}\right]=E\left[\log r_{t, n}^{k} \mid \psi_{t}\right]+\phi_{n}^{j k}
$$

where $\phi_{n k}^{j}$ is given by

$1 / 2 \operatorname{Var}\left[\log r_{t, n}^{k}+\log m_{t, n} \mid \psi_{t}\right]-1 / 2 \operatorname{Var}\left[\log r_{t, n}^{j}+\log m_{t, n}\left(\psi_{t}\right]\right.$. 
Since $\left\{x_{t}\right\}$ is a normally distributed stochastic process, the conditional expectations are linear functions. Further, the conditional variances are constants and, hence, $\phi_{n}^{j k}$ is a constant. Thus, by choosing $r_{t, n}^{j}$ to be the return from buying and holding an $n$-period, pure discount bond and choosing $r_{t, n}^{k}=_{s=t}^{t+n-1} r_{s, 1}$, which is the return from a strategy of rolling over a sequence of $n$ one-period, pure discount bonds, we obtain a log-linear, return-to-maturity expectations model of the real term structure of interest rates with a constant intercept $\phi_{n}^{j k}$ :

$$
E\left[\log r_{t, n}^{j} \mid \psi_{t}\right]=\sum_{s=t}^{t+n-1} E\left[\log r_{s, 1} \mid \psi_{t}\right]+\phi_{n}^{j k}
$$

By expressing $r_{t, n}^{j}$ as $\left(y_{t, n}\right)^{n}$, where $y_{t, n}$ is (one plus) the yield to maturity on the n-period, pure discount bond, we obtain

$$
E\left[\log y_{t, n} \mid \psi_{t}\right]=\sum_{n}^{1} \sum_{s=t}^{t+n-1} E\left[\log r_{s, 1} \mid \psi_{t}\right]+\sum_{n}^{1} \phi_{n}^{j k}
$$

which is a version of the familiar expectations model for yields to maturity, with a constant intercept $\frac{1}{n} \phi_{n}^{j k}$. The constant $\phi_{n}^{j k}$ is sometimes referred to as a risk premium associated with n-period securities. However, while $\phi_{n}^{j k}$ is a constant, the conditional covariance in ( 6 ) is in general not a constant under the assumption of lognormality. Thus, a risk premium defined in terms of the levels of returns and $m_{t, n}$ is time-varying in this model. These log-linear, expectations models can be expressed as linear expectations models in terms of continuously compounded returns.

Gutil recently, attention was focused primarily on versions of the expectations model, with perhaps the most attention being given to the linear expectations model, which states that the expected yield-to-maturity on a long-term bond is an average of the expected returns of future one-period bonds. Roll (1970), Shiller (1979), Singleton (1980), Hansen and Sargent (1981), and Shilier, Campbell, and Schoenholtz (1983), among others, have provided substantial empirical evidence against linear expectations models using yields on nominal bonds.

7 A time series $\left\{x_{t}\right\}$ is strictly stationary if the marginal distribution of $\left(x_{t_{1}}, \ldots x_{t_{n}}\right)$ is the same as the distribution of $\left(x_{t_{1}+\tau}, \ldots x_{t_{n}+\tau}\right)$ for 
all $t_{1}, \ldots t_{n}, \tau$. This does not require that moments of conditional distributions be constant. A brief discussion of the estimation procedures is presented in section four; see Hansen and Singleton (1982) for details. For instruments we used the constant unity, lagged values of the per capita growth rate of real consumption of nondurables plus services, and lagged values the real rates of return on the two securities. For each return, there were five orthogonality conditions used to estimate two parameters, leaving three overidentifying restrictions to be tested.

${ }^{8}$ Constantinides and Ingersoll (1984) and Dammon (1983) discuss some of the implications for bond pricing of taxes in an environment with heterogeneous investors.

${ }^{9}$ Similar utility functions were studied by Kydland and Prescott (1982) and Eichenbaum, Hansen, and Singleton (1983). They assumed preferences were defined over consumption of nondurable goods and leisure; consumption of durable goods did not enter explicitly. Here we include durable goods, but omit leisure choices thereby assuming that utility is separable across leisure and consumption goods.

\footnotetext{
10 We have chosen to normalize $\alpha_{0}$ to be unity instead of requiring that $\mathrm{n}$

$\sum_{j=1} \alpha_{j}=1$. Our analysis is invarient to the particular normalization chosen.
}

${ }^{11}$ A sufficient condition for the polynomial in the lag operator to have a one-sided inverse is that all of the roots of the polynomial lie outside the unit circle (i.e., have absolute value greater than one).

12 only the taxation of ordinary income is considered, since short term bonds are studied in this paper. Also, in the subsequent discussion, the tax rate may depend on the level of nominal income, but the returns are after-tax real rates of return.

${ }^{13}$ Interestingly, Hansen, Richard, and Singleton (1981) rejected this version of the time-separable model at small marginal significance levels, using monthly stock returns. Their findings provide further support for our claim in section two that the evidence against this class of models is not due entirely to mismeasurement of consumption.

14 When investments over different holding periods are studied, the disturbances in the associated estimation equations will have correspondingly different autocovariance structures. For instance, the disturbance in the equation for the three-month bill discussed in section two follows a moving average process of order two and the disturbance in the equation for the one-month bill is serially uncorrelated. This fact was taken into account in both the estimation and inference.

15 This estimate of the initial stock of durable goods is less than ideal since it is based on the assumption of straight-line depreciation, which is inconsistent with the geometric decay implicit in (10). It can be 
shown however that, under the assumption of invertible lag polynomials in (15), and certain regularity conditions on the capital stock, mismeasurement of the initial stock does not affect the large sample properties of the estimates or test statistics.

${ }^{16}$ This interpretation was suggested to us by Doug Breeden.

${ }^{17}$ We also estimated the model with the order of the returns reversed (i.e. with $z_{2 t}$ given by (28) and $z_{\text {it }}$ consisting of the single instrument unity) and found that the results reported in Table III are insensitive to this reversal.

${ }^{18}$ Unfortunately, attempts to estimate the parameter using only returns in difference form failed in that the minimization algorithm did not converge.

${ }^{19}$ Both the point estimates and the test statistics for the model with $m=2$ were sensitive to the choice of starting values and the estimate of the weighting matrix. Nevertheless, the results from all of the runs with $m=2$ were qualitatively the same and as described in the text.

${ }^{20}$ The estimated pairs (ER, RP) obtained using the point estimates from the runs in Table II are: $E R=-3.0378-05$ and $R P=1.3575-05$ for TBILL3; and $E R=4.7314-04$ and $R P=1.2543-05$ for $T B 6 H 3$.

21 This finding suggests that there is a positive relation among $|\gamma|$ and the average value of the riskfree real rate in our model, $E\left[M U_{C}^{*}(t) / M U_{C}^{*}(t+3)\right]$. Verification of this relation in our model is not possible, however, because the riskfree rate involves agents' conditional expectations. Mehra and Prescott (1983) obtained a positive relation between risk aversion and the average riskfree real rate in the context of their single-good model with time-separable utility. 


\section{REFERENCES}

D. T. Breeden. "An Intertemporal Asset Pricing Model with Stochastic Consumption and Investment Opportunities." Journal of Financial Economics 7 (September 1979), 265-296.

D. T. Breeden. "Interest Rates in a Multi-Good Economy." Research Paper No. 719, Stanford University (December 1983).

D. T. Breeden. "Consumption, Production, and Interest Rates: A Synthesis." Research Paper No. 667, Stanford University (January 1984).

D. T. Breeden and R. H. Litzenberger. "Prices of State-contingent Claims Implicit in Option Prices." Journal of Business 51 (Ocboter 1978), $621-651$.

W. A. Brock. "Asset Prices in a Production Economy." in J. J. McCall (e.d.). The Economics of Uncertainty. Chicago: University of Chicago Press, 1980.

D. P. Brown and M. R. Gibbons. "A Simple Econometric Approach for Utility-Based Asset Pricing Models." manuscript, Indiana University, March 1983.

G. M. Constantinides. "Capital Market Equilibrium with Personal Tax", Econometrica 51 (1983), 611-636.

G. M. Constantinides and J. E. Ingersoll, Jr., "Optimal Bond Trading with Personal Taxes: Implications for Bond Prices and Estimated Tax Brackets and Yield Curves", Journal of Financial Economics (forthcoming, 1984).

B. Cornel1, "The Consumption Based Asset Pricing Model: A Note on Potential Tests and Applications." Journal of Financial Economics 9 (March 1981), 103-108.

J. C. Cox, J. E. Ingersoll, Jr., and S. A. Ross. "A Theory of the Term Structure of Interest Rates." Research Paper No. 468, Stanford University, 1978, (fortheoming in Econometrica).

J. C. Cox, J. E. Ingersoll, Jr., and S. A. Ross. "A Reexamination of the Traditional Hypotheses About the Term Structure of Interest Rates." Journal of Finance 36 (September 1981), 769-799.

R. M. Dammon. "Portfolio Selection, Capital Structure, and Taxes: A State-Preference Approach," manuscript, University of Wisconsin Madison, November 1983.

K. E. Dunn and K. J. Singleton. "A Empirical Analysis of the Pricing of Mortgage-Backed Securities." Journal of Finance 38 (May 1983), 613-623. 
M. S. Eichenbaum and L. P. Hansen. "Uncertainty, Aggregation, and the Dynamic Demand for Consumption Goods." manuscript, Carnegie-Melion University, 1984.

M. S. Eichenbaum, L. P. Hansen and K. J. Singleton. "A Time Series Analysis of Representative Agent Models of Consumption and Leisure Choices under Uncertainty." manuscript, Carnegie-Mellon University, 1983.

W. E. Ferson. "Expectations of Real Interest Rates and Aggregate Consumption: Empirical Tests." Journal of Financial and Quantitative Analysis 18 (December 1983), 477-497.

S. Grossman and R.J. Shiller. "The Determinants of the Variability of Stock Market Prices." American Economic Review 71 (May 1981), 222-227.

L. P. Hansen. "Large Sample Properties of Generalized Method of Moment Estimators." Econometrica 50 (July 1982) 1029-1054.

L. P. Hansen, S.F. Richard and K.J. Singleton. "Econometric Implications of Intertemporal Asset Pricing Models." manuscript, Carnegie-Mellon University, 1981.

L. P. Hansen and K. J. Singleton. "Generalized Instrumental Variables Estimation of Nonlinear Rational Expectations Models." Econometrica 50 (Sep tember 1982), 1269-1286.

L. P. Hansen and K. J. Singleton, "Stochastic Consumption, Risk Aversion and the Temporal Behavior of Asset Returns." Journal of Political Economy 91 (April 1983), 249-265.

L. P. Hansen and T. J. Sargent. "Exact Linear Rational Expectations Models: Specification and Estimation." Federal Reserve Bank of Minneapolis, Staff Report 71, September 1981.

J. Huisinga and F. S. Mishkin. "The Measurement of Short-Term Real Interest Rates on Assets with Different Risk Characteristics." manuseript, University of Chicago, May 1983.

R. G. Ibbotson and R. A. Sinquefield. Stocks, Bonds, Bilis and Inflation: The Past and the Future. The Financial Analysts Research Foundation, 1982.

F. E. Kydland and E. C. Prescott. "Time to Build and Aggregate Fluctuations." Econometrica 50 (November 1982), 1345-1370.

R. E. Lucas, Jr. "Asset Prices in an Exchange Economy." Econometrica 46 (November 1978), 1429-1446.

R. E. Lucas, Jr. "Money in a Theory of Finance," manuscript, Univeriy of Chicago, 1983.

T. A. Marsh. "Capital Asset Pricing Model Tests in a Term Structure Context (March 1983). 
R. Mehra and E. C. Prescott. "A Test of the Intertemporal Asset Pricing Model." Manuscript, Columbia University, 1983.

J. C. Musgrave. "Durable Coods Owned by Consumers in the United States, 1925-1977." Survey of Current Business (March 1979).

E. C. Prescott and R. Mehra. "Recursive Competitive Equilibrium: The Case of Homogeneous Households." Econometrica 48 (September 1980), $1365-1380$.

S. F. Richard and M. Sundaresan. "A Continuous Time Equilibrium Model of Forward Prices and Future Prices in a Multigood Economy." Journal of Financial Economics 9 (December 1981), 347-371.

K. RoII. The Behavior of Interest Rates. Basic Books (New York, 1970).

M. Rubinstein. "The Valuation of Uncertain Income Streams and the Pricing of Options." Bell Journal of Economics and Management Science 7 (Autumn 1976), 407-425.

R. J. Shiller. "The Volatility of Long-Term Interest Rates and Expectations Models of the Term Structure." Journal of Political Economy 87 (December 1979), 1190-1219.

R. J. Shiller, J. Y. Campbell, and K. L. Schoenholtz. "Forward Rates and Future Policy: Interpreting the Term Structure of Interest Rates." Cowles Foundation Discussion Paper No. 667, Yale University, June 1983.

K. J. Singleton. "Expectations Models of the Term Structure and Implied Variance Bounds." Journal of Political Economy 88 (December 1980), 1159-1176.

K. J. Singleton. "Testing Specifications of Economic Agents" Intertemporal Optimum Problems Against Non-nested Alternatives." Manuseript, Carnegie-Melion University, 1984.

M. Sundaresan. "Consumption and Equilibrium Interest Rates in Stochastic Production Economies," Journal of Finance 39 (March 1984), 77-92.

L. G. Telser and R. L. Graves. Functional Analysis in Mathematical Economics. The University of Chicago Press (Chicago, 1972). 